\title{
Comparison of "Polynaphthalenes" Prepared by Two Mechanistically Distinct Routes
}

\author{
James P. Johnson, Dustin A. Bringley, Erin E. Wilson, Kevin D. Lewis, Larry W. Beck, \\ and Adam J. Matzger*
}

Department of Chemistry and the Macromolecular Science and Engineering Program, The University of Michigan, Ann Arbor, Michigan 48109-1055, USA. Fax: (734) 615-8853; Tel: (734) 615-6627

All reactions were conducted under a $\mathrm{N}_{2}$ atmosphere and monitored by TLC or GC. THF and benzene were dried by passing through an activated alumina column and deoxygenated by sparging with $\mathrm{N}_{2}$. $o$-Bis(trimethylsilylethynyl)benzene was prepared by the published procedure. ${ }^{1}$

MALDI-TOF MS sample preparation: Samples utilizing matrix were mixed in an 8:1 ratio (by mass) of dithranol to sample and thoroughly ground. Samples without matrix were simply ground into a powder. The material was deposited directly to the target plate, and excess solid was removed by blowing with a gentle stream of $\mathrm{N}_{2}$ over the plate before analysis. Spectra were collected using a Micromass Tof Spec 2E equipped with a $337 \mathrm{~nm}$ nitrogen laser (funded with NSF grant DBI 99874). Each mass spectrum is a composite of 25 spectra (each an average of five shots).

Pyrolysis GC-MS: Samples were pyrolyzed at $800{ }^{\circ} \mathrm{C}$ for $15 \mathrm{~s}$ followed by separation with an Agilent HP-INNOWax column $(60 \mathrm{~m} \times 0.25 \mathrm{~mm} \times 0.5 \mu \mathrm{m})$ with a temperature gradient $\left(40{ }^{\circ} \mathrm{C}\right.$ for 10 minutes, ramped at $15^{\circ} \mathrm{C}$ per min to $220{ }^{\circ} \mathrm{C}$, and held for $15 \mathrm{~min}$ ) and analyzed by an Agilent 5972 quadrapole mass spectrometer.

$\alpha$-Ternaphthyl was prepared in the manner of Andersen ${ }^{2}$ and had an IR absorption spectrum and melting point in agreement with the literature values mp 190-192 ${ }^{\circ} \mathrm{C}$ (lit. $\left.191-192{ }^{\circ} \mathrm{C}\right) .{ }^{3} \mathrm{IR}(\mathrm{KBr}): 3054$ (w), $3042(\mathrm{w}), 1506(\mathrm{w}), 1376(\mathrm{~m}), 948(\mathrm{w}), 848(\mathrm{w}), 802$ (s) 778 (s) 760(s) cm $\mathrm{cm}^{-1}$. 
Poly(1,4-dibromonaphthalene). ${ }^{4}$ To a dry flask was added 1,4-dibromonaphthalene (1.914 g, 7.478 $\mathrm{mmol}), \mathrm{Mg}(0.185 \mathrm{~g}, 7.62 \mathrm{mmol})$, and THF $(34 \mathrm{~mL})$. Once the Grignard reagent was generated, nickel(II) bis(acetylacetonate) $(9.8 \mathrm{mg}, 0.038 \mathrm{mmol})$ was added, and the black solution was stirred for $16 \mathrm{hrs}$ at RT followed by heating to reflux for $1 \mathrm{hr}$. The reaction was quenched by the addition of $1.3 \mathrm{M}$ hydrochloric acid in methanol $(20 \mathrm{~mL})$, and the product was collected by filtration. The precipitated polymer was subjected to sohxlet extraction with methanol for $1 \mathrm{hr}$ and further extracted with toluene for $24 \mathrm{hrs}$. The remaining polymer was dried in vacuo to yield $0.234 \mathrm{~g}(25 \%)$ of an ivory solid. IR (KBr): $3062(\mathrm{w}), 3037(\mathrm{~m}), 1506(\mathrm{~m}), 1370(\mathrm{~m}), 953(\mathrm{~m}), 837(\mathrm{~m}), 758(\mathrm{~s}) \mathrm{cm}^{-1}$.

o-Diethynylbenzene. To $o$-bis(trimethylsilylethynyl)benzene $(1.214 \mathrm{~g}, 4.488 \mathrm{mmol})$ was added methanol $(8.0 \mathrm{~mL})$ and $\mathrm{K}_{2} \mathrm{CO}_{3}(0.609 \mathrm{~g}, 4.98 \mathrm{mmol})$. After $1 \mathrm{hr}$, the solution was diluted with water (80 $\mathrm{mL})$, and the aqueous layer was extracted $(3 \times 25 \mathrm{~mL})$ with pentane. The combined organic layers were dried over $\mathrm{MgSO}_{4}$, and the solvent was removed by rotary evaporation. The residue was subjected to Kugelrohr distillation $\left(100{ }^{\circ} \mathrm{C}, 7\right.$ Torr $)$ to yield $0.489 \mathrm{~g}(86 \%)$ of $o$-diethynylbenzene as a pale yellow oil in greater than $99 \%$ purity by GC-FID.

Poly(o-diethynylbenzene). ${ }^{5}$ To an ampoule was added $o$-diethynylbenzene $(0.393 \mathrm{~g}, 3.12 \mathrm{mmol})$ and benzene $(2.5 \mathrm{~mL})$. The solution was subjected to three freeze-pump-thaw cycles and sealed. The ampoule was heated in a Parr reactor with pressure equalizing solvent to $170{ }^{\circ} \mathrm{C}$ for $14 \mathrm{hrs}$. After cooling, the polymer was collected by filtration and washed with distilled diethyl ether. The polymer was dried in vacuo to yield $0.378 \mathrm{~g}(97 \%)$ of a red-brown solid. IR (KBr): 3298 (w), 3060 (m), 3024 (m), 2104 (vw), $1596(\mathrm{~m}), 1476(\mathrm{~m}), 874(\mathrm{w}), 754(\mathrm{~s}) \mathrm{cm}^{-1}$.

Bromine uptake experiments. Brominations were performed by placing $10.33 \mathrm{mg}$ of poly (o-diethynylbenzene) in contact with a solution of bromine $\left(4.45 \mathrm{~mL}, 0.368 \mathrm{M}\right.$ in $\left.\mathrm{CH}_{2} \mathrm{Cl}_{2}\right)$. After 15 hrs, the solvent and remaining bromine were removed by rotary evaporation, and the residue was dried in vacuo until constant weight was achieved. The poly(o-diethynylbenzene) exhibited an $80 \%$ mass increase. The same procedure performed on poly(1,4-dibromonaphthalene) led to a $6 \%$ increase in mass. It is likely that the degree of unsaturation in the Bergman system is higher than our bromination 
experiment would indicate. For example, bromine adds to only $42 \%$ of the double bonds poly(phenylacetylene). ${ }^{6}$

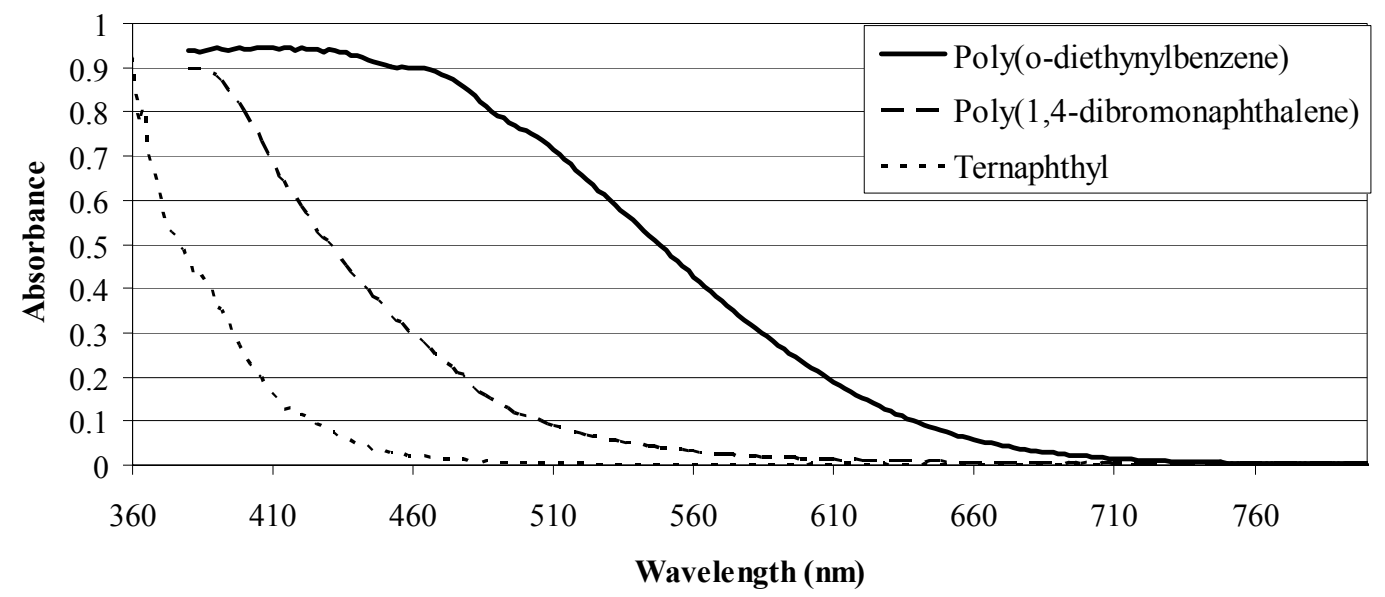

Normalized solid-state UV-vis spectra of $\alpha$-ternaphthyl, poly(1,4-dibromonaphthalene) and poly(o-diethynylbenzene). The relatively long wavelength of absorption for poly(o-diethynylbenzene) is inconsistent with a poly(1,4-naphthalene) structure because the torsion angles in the latter preclude a high level of conjugation.

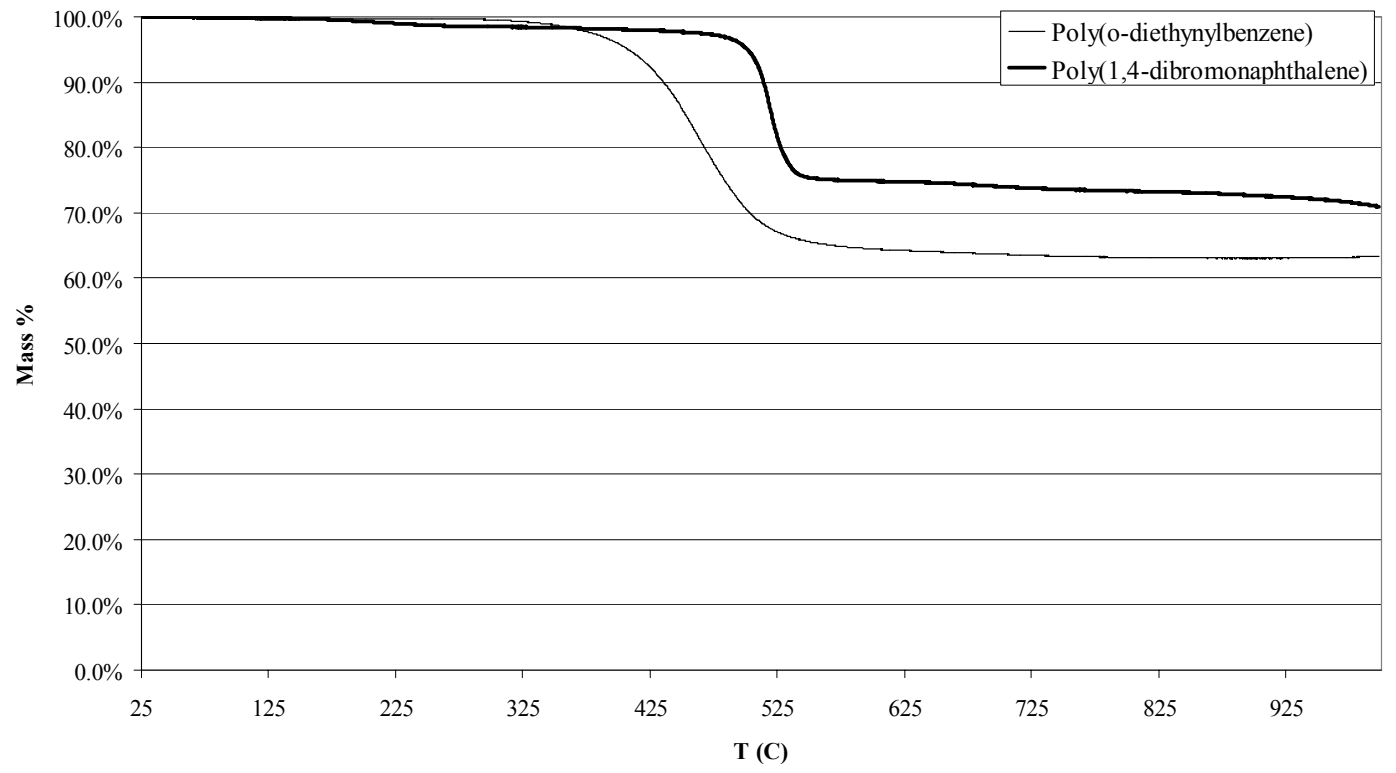

TGA traces of poly $\left(o\right.$-diethynylbenzene) and poly(1,4-dibromonaphthalene) obtained at $5{ }^{\circ} \mathrm{C}$ per minute under an $\mathrm{N}_{2}$ purge from $\mathrm{RT}$ to $1000^{\circ} \mathrm{C}$. 


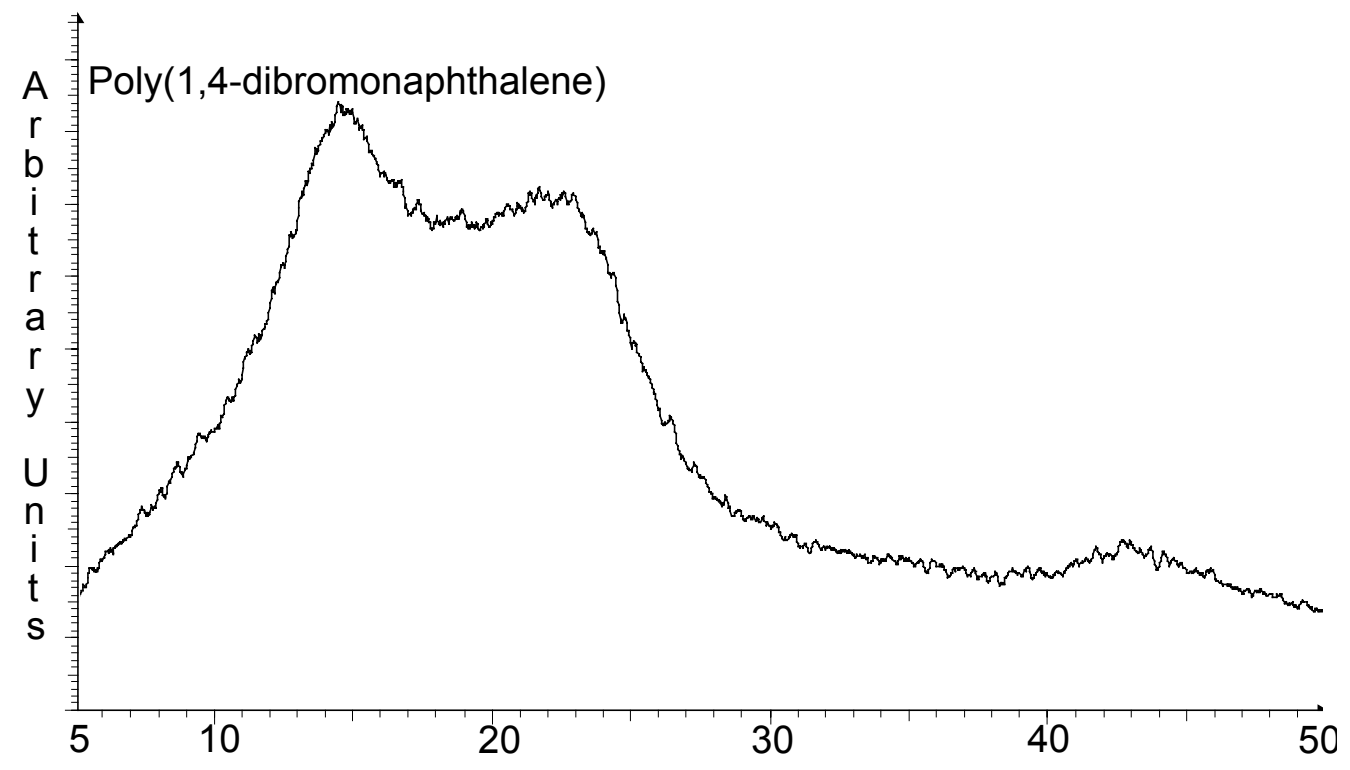

2-Theta

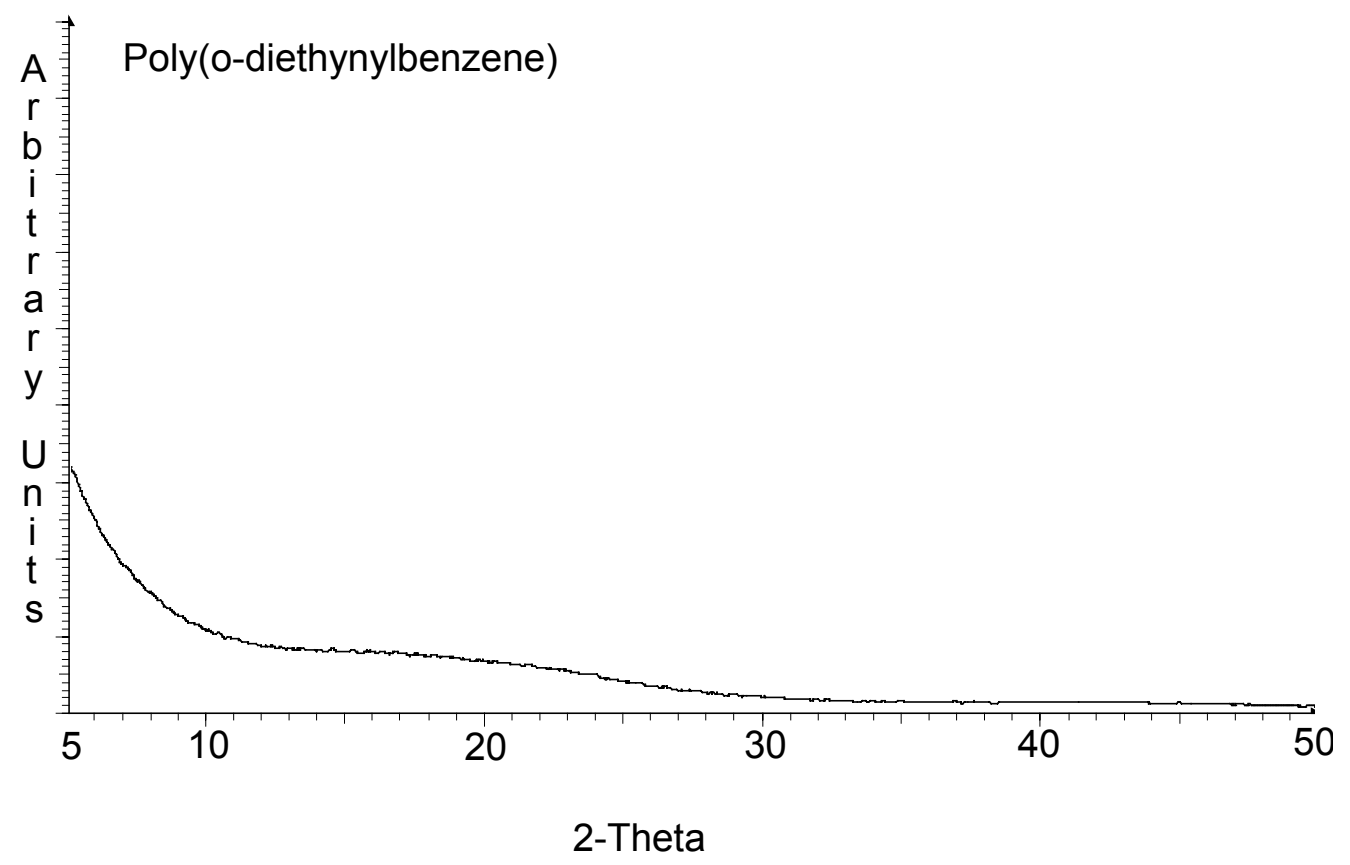

Powder X-ray diffraction patterns of poly(1,4-dibromonaphthalene) and poly(o-diethynylbenzene). The powder pattern of the poly(1,4-dibromonaphthalene) shows three relatively defined peaks whereas poly(o-diethynylbenzene) gives rise to one broad peak in addition to considerable low angle scattering, demonstrating that the poly(1,4-dibromonaphthalene) is more ordered. 

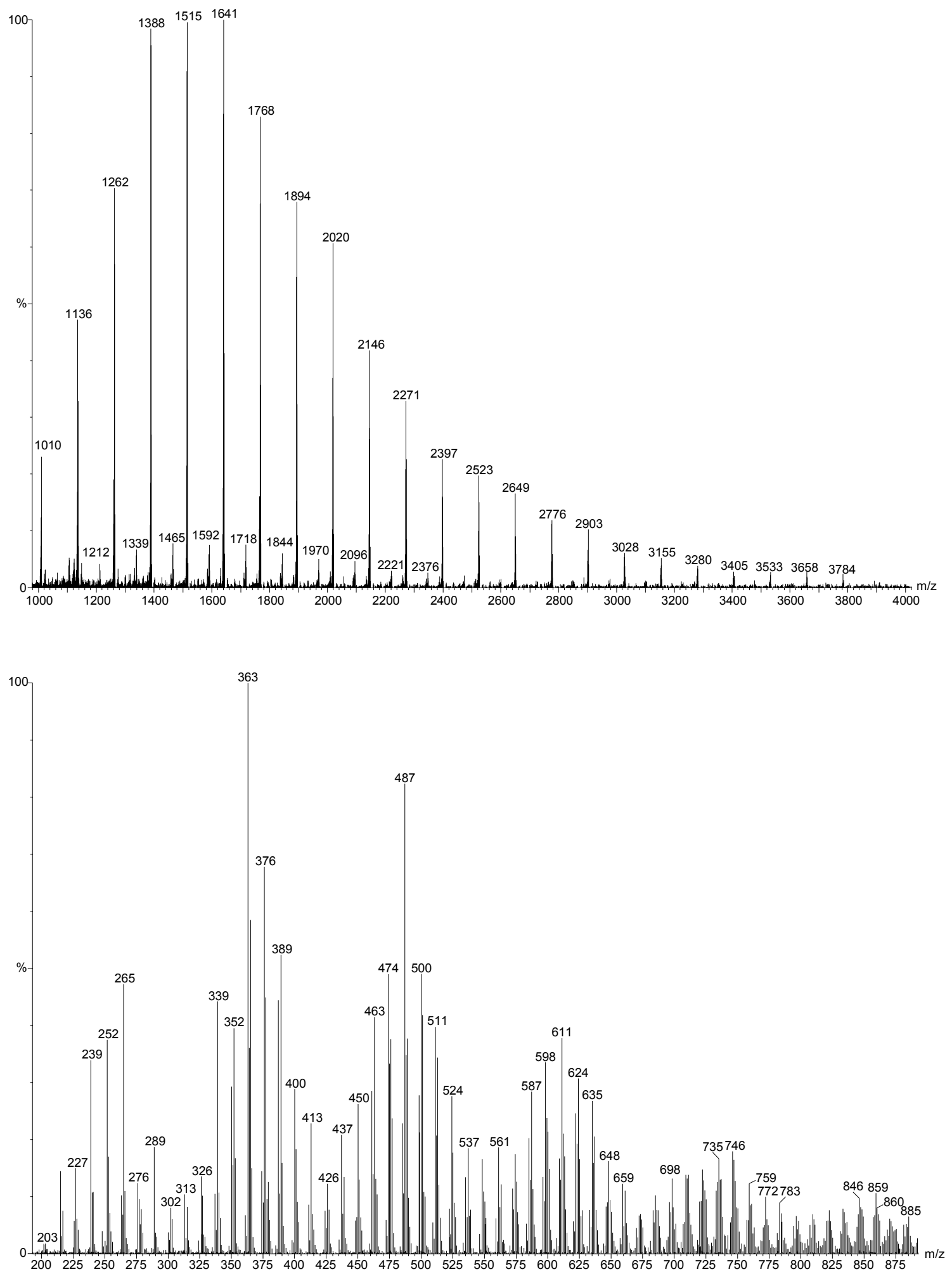

MALDI-TOF MS data of poly(1,4-dibromonaphthalene) (top) and LDI-TOF MS data of poly(o-diethynylbenzene) (bottom). Note: For poly(1,4-dibromonaphthalene) the isotope patterns lead to peak separations that are not exactly 126 mass units for the most intense peaks in the isotope packet. 


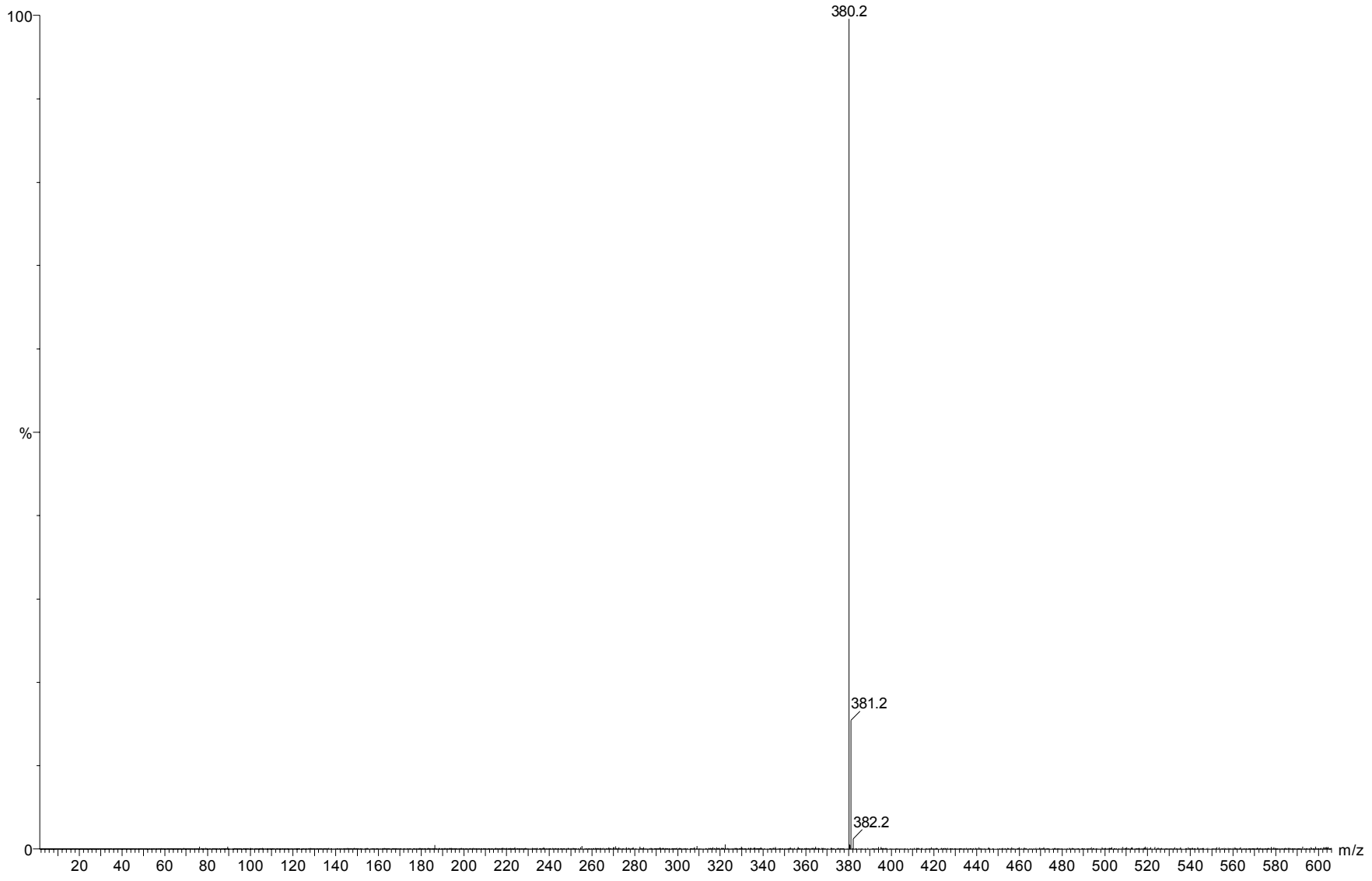

\section{LDI-TOF MS data of $\alpha$-ternaphthyl.}




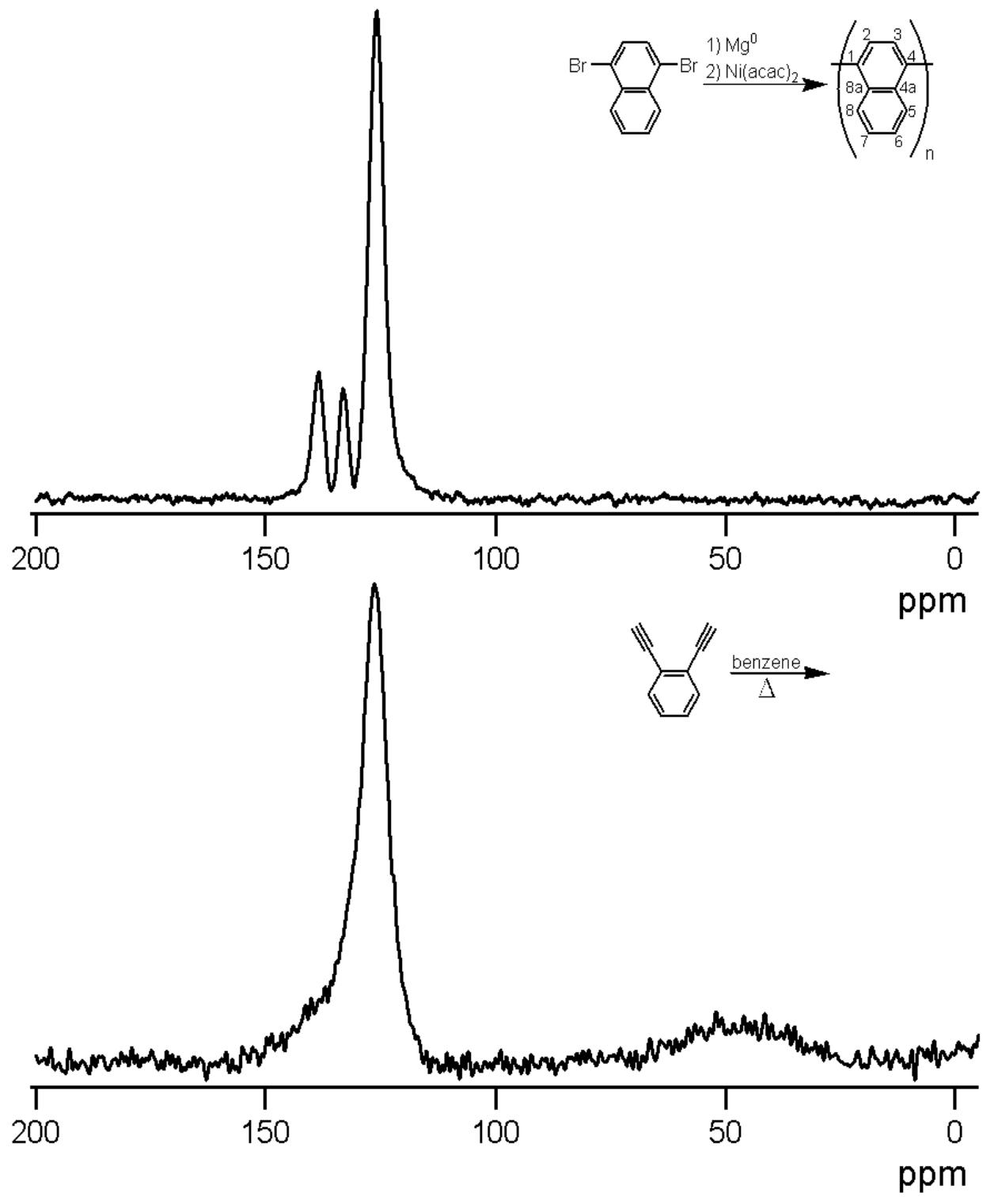

${ }^{13} \mathrm{C}$ CP-MAS NMR spectra of poly(1,4-dibromonaphthalene), top, and poly(o-diethynylbenzene), bottom. Both spectra were obtained under fast MAS, $\mathrm{v}_{\mathrm{r}}=10 \mathrm{kHz}$ using a relatively short contact time, $360 \mu \mathrm{s}$. The polarization transfer condition was set so that the carbon nutation field was set to the -1 spinning sideband of the proton Hartman-Hahn condition. These conditions gave the most quantitative peak intensities for the poly(1,4-dibromonaphthalene). 


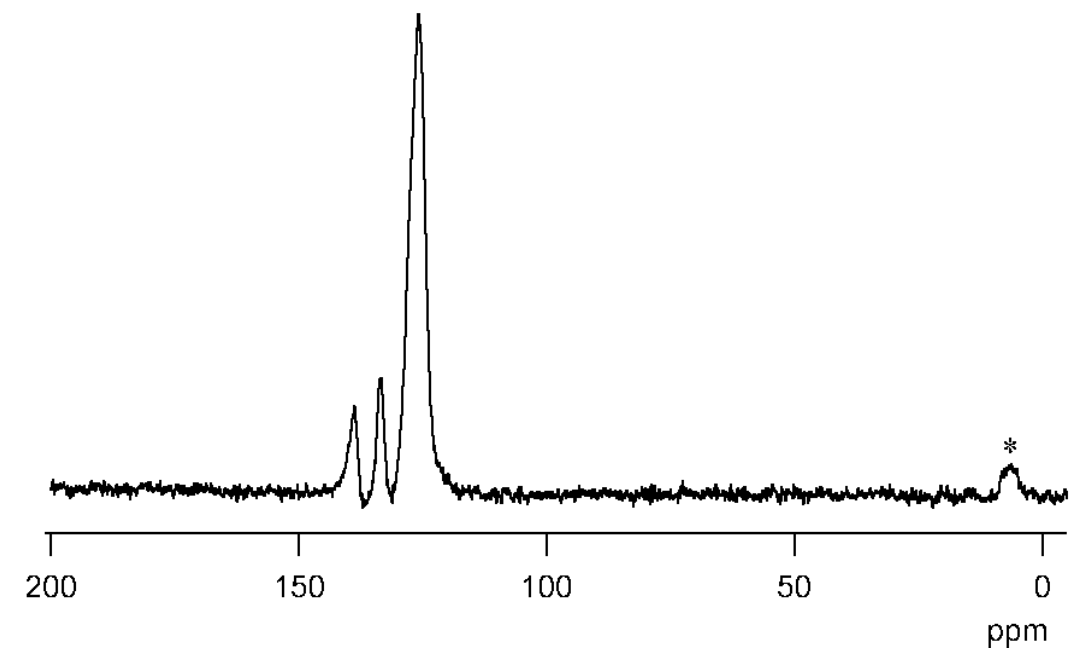

${ }^{13}$ CP-MAS NMR spectra of $\alpha$-ternaphthyl. The peak labeled with an asterisk is a spinning sideband.

(1) Takahashi, S.; Kuroyama, Y.; Sonogashira, K.; Hagihara, N. Synthesis 1980, 627-630.

(2) Andersen, N. G.; Maddaford, S. P.; Keay, B. A. J. Org. Chem. 1996, 61, 9556-9559.

(3) Kovacic, P.; Koch, F. W. J. Org. Chem. 1965, 30, 3176-3181.

(4) Sato, M. A.; Kaeriyama, K.; Someno, K. Makromol. Chem. 1983, 184, 2241-2249.

(5) John, J. A.; Tour, J. M. J. Am. Chem. Soc. 1994, 116, 5011-5012.

(6) Cataldo, F. Eur. Polym. J. 1992, 28, 1493-1499. 